Fanum

Sociológico

\section{Forum Sociológico}

Série II

$18 \mid 2008$

Explorando os interstícios urbanos

\title{
Espaços e práticas intersticiais de poder e resistência em Cardiff, País de Gales
}

\section{Ana Gonçalves}

\section{(2) OpenEdition}

1 Journals

Edição electrónica

URL: https://journals.openedition.org/sociologico/236

DOI: 10.4000/sociologico.236

ISSN: 2182-7427

Editora

CICS.NOVA - Centro Interdisciplinar de Ciências Sociais da Universidade Nova de Lisboa

\section{Edição impressa}

Data de publição: 1 junho 2008

Paginação: 29-37

ISSN: 0872-8380

\section{Refêrencia eletrónica}

Ana Gonçalves, «Espaços e práticas intersticiais de poder e resistência em Cardiff, País de Gales»,

Forum Sociológico [Online], 18 | 2008, posto online no dia 19 julho 2012, consultado o 31 março 2022 URL: http://journals.openedition.org/sociologico/236 ; DOl: https://doi.org/10.4000/sociologico.236

Este documento foi criado de forma automática no dia 31 março 2022.

(c) CICS.NOVA 


\title{
Espaços e práticas intersticiais de poder e resistência em Cardiff, País de Gales
}

\author{
Ana Gonçalves
}

\section{Introdução}

1 Os espaços nas cidades contemporâneas do mundo ocidental apresentam-se como paisagens onde o poder é construído e perpetuado e onde ritmos de apropriação individual e colectiva são impressos quotidianamente na malha urbana. 0 modo como os indivíduos apropriam estes espaços e participam nas actividades que a cidade lhes oferece constrói a sua percepção sobre a cidade e sobre a sua identidade cultural.

De acordo com Duncan (1990), a cidade é um texto onde os valores, as características pessoais e o poder são inscritos, e que possibilita tantas "leituras" quantas os seus "leitores". Assim sendo, cada indivíduo cria a sua própria "cidade interna" (Kavaratzis, 2004), ou seja, os diferentes sentimentos e experiências pessoais que permitem que cada sujeito compreenda a cidade de uma forma muito particular. Esta "cidade interna" é constituída pelas nossas experiências e percepções do espaço ("prática espacial e representações de espaço", Lefebvre, 1991b: 38), e pelos nossos espaços representacionais, isto é, os espaços directamente vividos através das imagens e símbolos que lhes estão associados (Lefebvre, 1991b: 39). Todavia, uma vez que reflectiremos neste artigo sobre o modo como o poder é construído na cidade contemporânea ocidental, devemos ter presente que, ao "lerem este texto" e ao tentarem compreender as cidades que visitam e onde vivem e trabalham, os indivíduos fazem-no interpretando, aperfeiçoando, resistindo, opondo-se ou até ignorando as atitudes prevalecentes do seu tempo, mas não sincronizando os seus pensamentos (Marien, 2002).

3 Após uma incursão teórica pela arte pública e pelo modo como é exibida nos espaços urbanos das cidades pós-modernas, este artigo procurará reflectir sobre os espaços e 
práticas urbanos de Cardiff, a capital do País de Gales, no Reino Unido, e compreender o modo como o poder e os discursos dominantes têm sido integrados na construção dos espaços desta cidade. Estes discursos, aparentemente consensuais e colectivamente partilhados, encontram-se ancorados nos projectos de regeneração urbana e em campanhas de promoção turística, aos quais subjaz o principal objectivo de tornar Cardiff uma capital Europeia apelativa, de características mundiais.

Cardiff foi um importante porto exportador de carvão durante o século XIX, acolhendo uma das mais importantes comunidades trabalhadoras multi-étnicas do mundo. Todavia, em meados do século XX, a desindustrialização levou ao abandono das docas. Consequentemente, durante as últimas décadas, a cidade tem tentado reinventar-se através de intensos processos de regeneração urbana e revitalização ribeirinha que têm transformado significativamente a paisagem económica, social e cultural da cidade, tendo as antigas áreas industriais sido substituídas por espaços e infraestruturas de entretenimento, comércio e restauração, acompanhados pelo rejuvenescimento de edifícios históricos, aos quais foram imputados novos usos, e pela construção de novos edifícios-âncora votados à cultura e ao lazer. As ruas e praças da cidade têm sido inscritas com novos símbolos e significados e o poder tem sido redistribuído nestes espaços, corroborando com um discurso dominante convincente e unificador.

\section{Espaços Urbanos e Arte Pública}

5 As cidades contemporâneas ocidentais constituem-se de espaços sujeitos a uma ideologia pós-moderna de consumo visual, em que a imagem se reveste de contornos marcadamente economicistas, no sentido de atrair capital humano, económico e simbólico à cidade. Com vista a um reposicionamento competitivo destas cidades no panorama mundial, a esta ideologia subjaz uma política de marketing territorial que promove a constante estruturação e reestruturação dos espaços urbanos, numa lógica capitalista de produção e reprodução, consumo e circulação (Fainstein e Campbell, 1996: 344), sendo estes espaços apropriados e consumidos como outro qualquer produto. Esta (re)estruturação revela-se crescentemente espectacular e decisiva na (re)construção da identidade cultural da cidade e da sua influência a nível mundial. De facto, segundo Waikeen e Ryser (2005: 16), é nos espaços cívicos, tais como ruas e praças, locais de reunião, interacção e observação, que se manifesta a identidade cultural da cidade. 0 modo como estes espaços são concebidos, adaptados, apropriados e preservados revela-se através dos ritmos quotidianos e da apropriação humana do ambiente físico que a rodeia; e expressa-se, por exemplo, através da arte que figura nestes espaços e que influi directamente na imagem que estes espaços transmitem aos que deles se apropriam.

6 A arte pública abrange muitas e diferentes formas de arte que são exibidas em locais de acesso público. Pode compreender formas mais permanentes, tais como estátuas ou obras de arte incorporadas nos edifícios, arte comemorativa, como seja o caso de memoriais, placas, inscrições, ou até murais, pavimentos e mobiliário urbano, assim como outras formas cuja exibição é transitória, como exposições, festivais e artes performativas de rua. Independentemente da forma que a obra de arte assume, a arte pública deve ser exibida num espaço que seja acessível e partilhado por todos. Consequentemente, apresenta-se como uma forma de arte exibida em espaços não convencionais (Miles, 1997: 2), ficando, por isso, habitualmente fora dos museus e 
galerias, onde os objectos de arte são codificados segundo um discurso e uma ideologia específicos.

7 A arte pública destina-se a criar espaços públicos atractivos, a narrar a(s) es-/história(s) da cidade e a construir e inscrever a identidade cultural nacional, imbuída da ideologia do Estado, nos espaços físicos urbanos, criando um discurso oficial unificador. Devemos, pois, questionar-nos se a arte pública é, de facto, partilhada por todos. As obras de arte exibidas nos espaços públicos são, de um modo geral, financiadas pelo Estado e representativas da cultura da cidade; mas será que todas as audiências compreendem o que contemplam e o modo como a sua percepção é construída (especialmente quando a arte pública não abarca a expressão das comunidades da cidade, aqueles que verdadeiramente se apropriam dos seus espaços no decurso das suas práticas quotidianas)?

8 A arte pública é habitualmente exibida nas ruas e praças, locais onde a "experiência vivida e a soma total das relações que constituem o ser humano" têm lugar (Lefebvre, 1991a: 97). A rua, por exemplo, apresenta-se como um local de observação por excelência que permite compreender a cultura urbana e os diferentes modos de construção intelectual e cultural da cidade (Cordeiro e Vidal, 2008). Na rua as pessoas observam, são observadas e partilham o espaço, adaptam-se a ele e adaptam-no a elas próprias e às relações que estabelecem com os outros. A rua é, pois, parte integrante do espaço social, onde existir "é ser diferente" (Bourdieu, 2001: 9) e onde as relações com os diferentes membros da vida social local têm lugar. Apesar de aparentemente neutra, sem proprietário, um local comum e diariamente partilhado, é transformada por aqueles que nela caminham e que a humanizam com a sua presença e com as suas "tácticas e estratégias" sociais e culturais (Certeau, 1984: 34-39). Para Certeau, a vida social e cultural na cidade incide não apenas na interacção social per se, mas também nas características das relações que se constituem entre os indivíduos e os espaços que ocupam (Certeau, 1984).

\section{Cardiff: A Construção de Uma Cidade Portuária Multiétnica}

9 A cidade de Cardiff, na sua aparência actual, em pouco se assemelha ao pequeno porto que era no século XIX. Através da construção de diferentes docas, financiadas por John Crichton Stuart, o segundo Marquês de Bute, Cardiff foi apelidada de "metrópole mundial de carvão" em meados do século XIX. As docas permitiram dar resposta ao crescente tráfego de cargueiros que aportavam a Cardiff para se abastecerem de carvão que se destinava a diferentes partes do mundo, e contribuíram para a reputação da cidade enquanto porto, especialmente entre 1850 e 1914.

10 As diversas oportunidades de trabalho nas indústrias mineira e naval e em outras actividades relacionadas com as docas atraíram mão-de-obra estrangeira a Cardiff. Muitos marinheiros de diferentes países fixaram-se na área residencial das docas e entrosaram-se com a população residente, constituindo família com mulheres galesas e criando uma comunidade multiétnica. Com o apoio filantrópico do Marquês de Bute, o bairro da classe trabalhadora multiétnica de Butetown começou a estruturar-se na área ribeirinha de Cardiff. Inicialmente construído para alojar profissionais da classe média, 
foi posteriormente ocupado por membros da classe trabalhadora, cujas ocupações se encontravam estreitamente associadas às docas.

11 No entanto, foi como Tiger Bay, aquele que era o nome comummente referenciado nos média britânicos, que esta comunidade passou a ser conhecida internacionalmente. Este nome era igualmente usado com conotações pejorativas para referir a comunidade que vivia na área e as pobres condições de habitação, saúde e educação que caracterizavam o bairro, para além do crime, vício e prostituição que se dizia existir na área.

Figura 1: Docas de Cardiff, c. 1900 (Visit Cardiff)

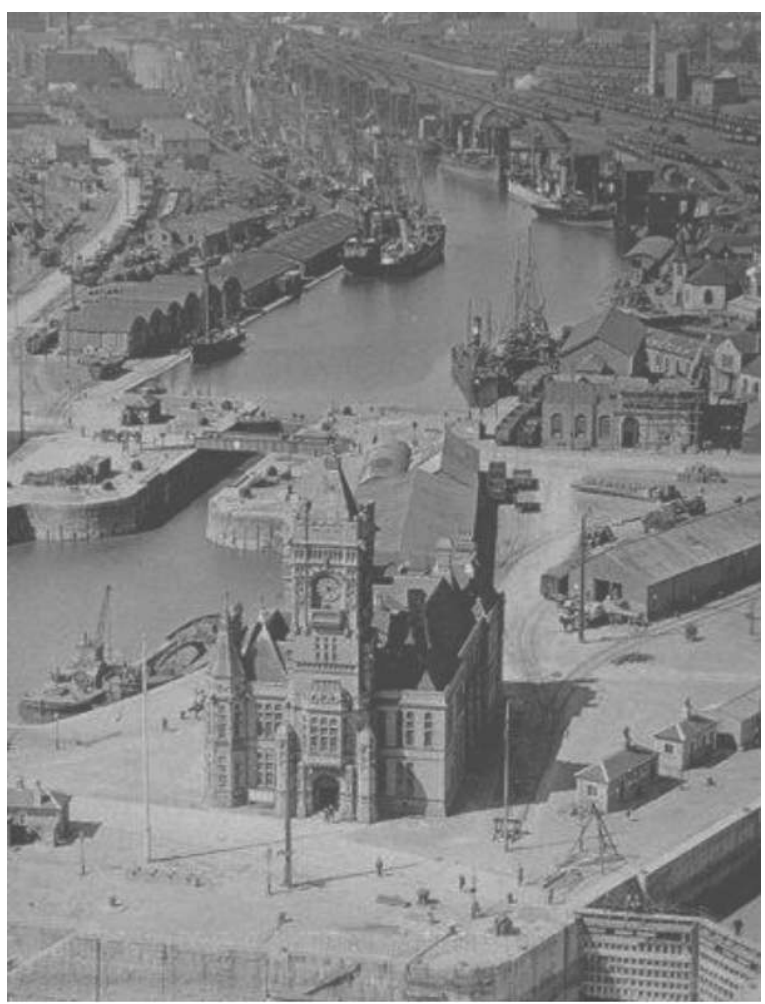

Estima-se que em 1950 este bairro acolhesse cerca de 6000 pessoas de 57 nacionalidades diferentes (Lloyd, 1950), que viviam numa área de pouco mais de 1,5 km de extensão. Devido à sua diversidade étnica e cultural e às suas relações laborais, estas pessoas partilhavam práticas de identificação quotidianas (Mulhern, 1998) na rua, onde interagiam e participavam nas actividades diárias da comunidade. Para estas pessoas, a rua era um espaço aberto a todos, verdadeiramente democratizado, onde a interacção social tinha lugar.

\section{A Regeneração de Uma Cidade Pós-Industrial}

13 Com o início do século $\mathrm{XX}$, o carvão foi sendo progressivamente substituído por petróleo como forma de combustível e Cardiff foi perdendo gradualmente a sua importância e prestígio enquanto porto de fileira, ao mesmo tempo que era ameaçada pelos portos vizinhos de Penarth e Barry, o que levou ao abandono das suas docas. 
Figura 2: Uma rua de Tiger Bay, 1957 (in O'Neill, 2001: 184)

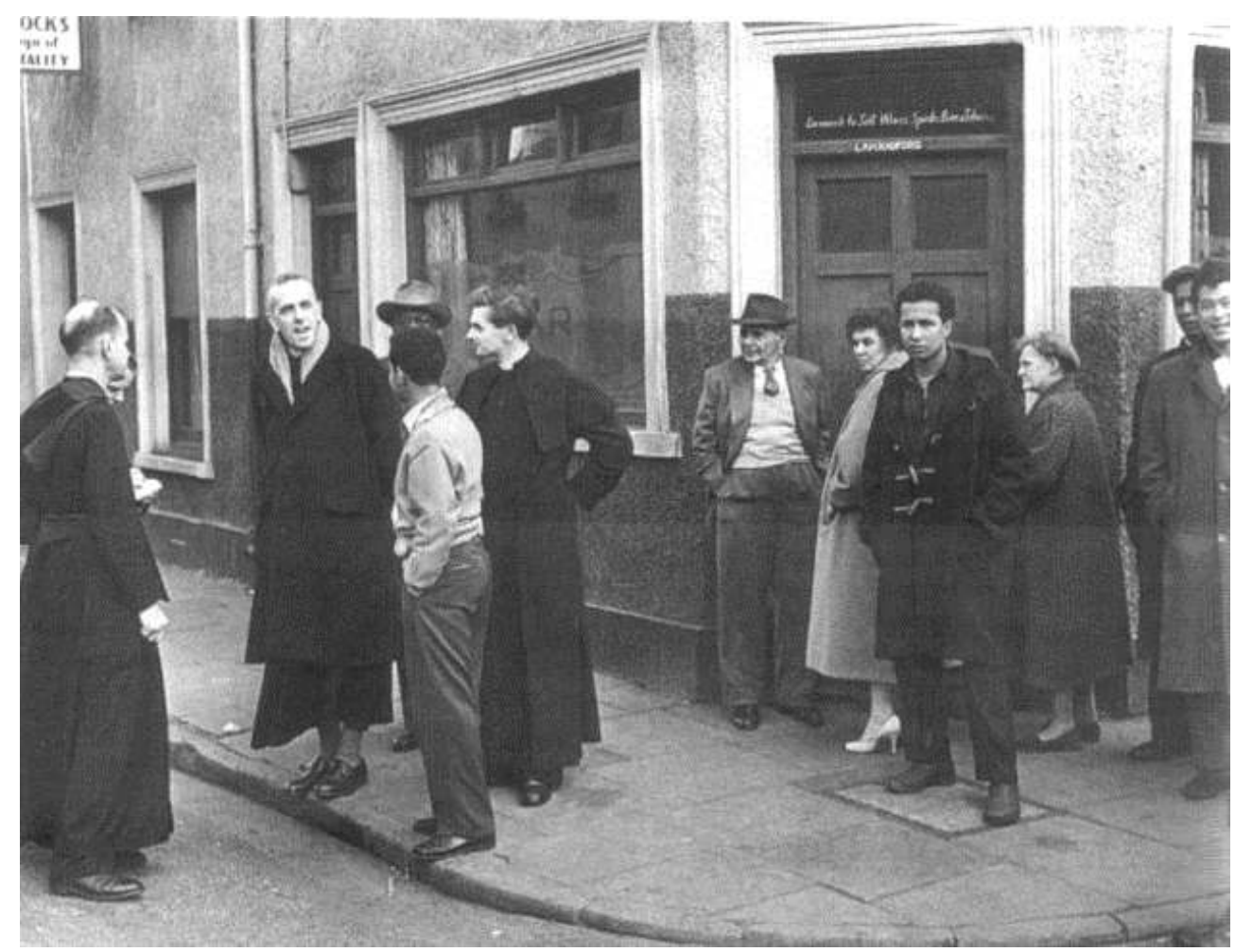

14 Tal situação conduziu igualmente ao aumento do desemprego no seio das comunidades trabalhadoras portuárias, cujos residentes estavam directa ou indirectamente dependentes de actividades relacionadas com as docas. Além disso, a adversidade imposta pelas Primeira e Segunda Guerras Mundiais intensificou as condições de privação em que os membros desta comunidade viviam e o processo de desindustrialização que levou à esterilidade das docas e à perda da sua vivacidade e prosperidade de outrora.

150 abandono das docas esteve igualmente na origem das primeiras estratégias de regeneração para revitalizar a frente ribeirinha da cidade, em finais da década de 50 do século XX. As primeiras transformações urbanas tiveram lugar em Loudoun Square, o "coração negro" de Butetown, onde a praça e as casas de dois andares que a circundavam foram demolidas e substituídas por edifícios de vários andares, dilacerando o espírito de comunidade que existia no bairro, tendo sido os seus residentes realojados na periferia da cidade ou nos subúrbios. 
Figura 3: Edifícios em Loudoun Square, início de 1960 (in Sinclair, 2003: 157)

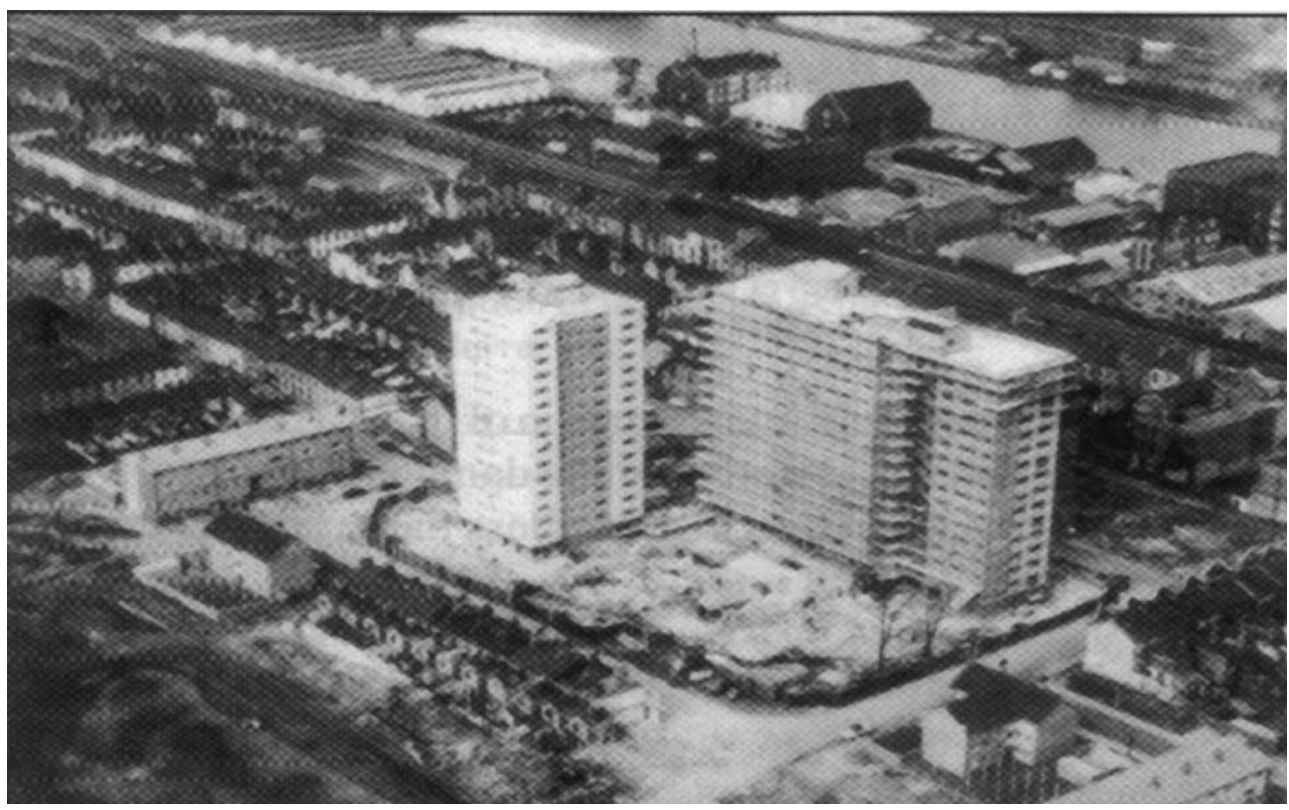

No entanto, foi apenas em 1987 que toda a estratégia de regeneração urbana e revitalização ribeirinha da cidade foi delineada, com a criação da Cardiff Bay Development Corporation (CBDC). A CBDC tornou-se responsável pela política e regeneração urbanas em Cardiff, tendo como principal intuito tornar Cardiff internacionalmente reconhecida enquanto cidade marítima de excelência, comparável a qualquer outra cidade do mundo (Rowley, 1994: 269), criando uma nova paisagem económica na frente de água de Cardiff que fosse apelativa para todos. O empreendimento deste objectivo tornou-se possível apenas através da construção da barragem na baía de Cardiff, em 1999, que veio criar um lago de água salgada, substituindo os inestéticos bancos de areia que caracterizavam a baía. No entanto, este foi possivelmente o desenvolvimento mais polémico na história de Cardiff, devido ao elevado investimento associado e ao alegado impacto ambiental nas espécies de aves que se alimentavam nos bancos de areia do estuário.

17 Esta nova baía permitiu, todavia, a revitalização da frente ribeirinha de Cardiff e a produção de novos espaços urbanos, bem como a renovação de edifícios históricos que ganharam novos usos e significados. Como tal, Cardiff tem sabido reinventar a sua baía, investindo-a de novos valores económicos, sociais, culturais e simbólicos. 
Figura 4: Barragem da Baía de Cardiff (in Cardiff Harbour Authority)

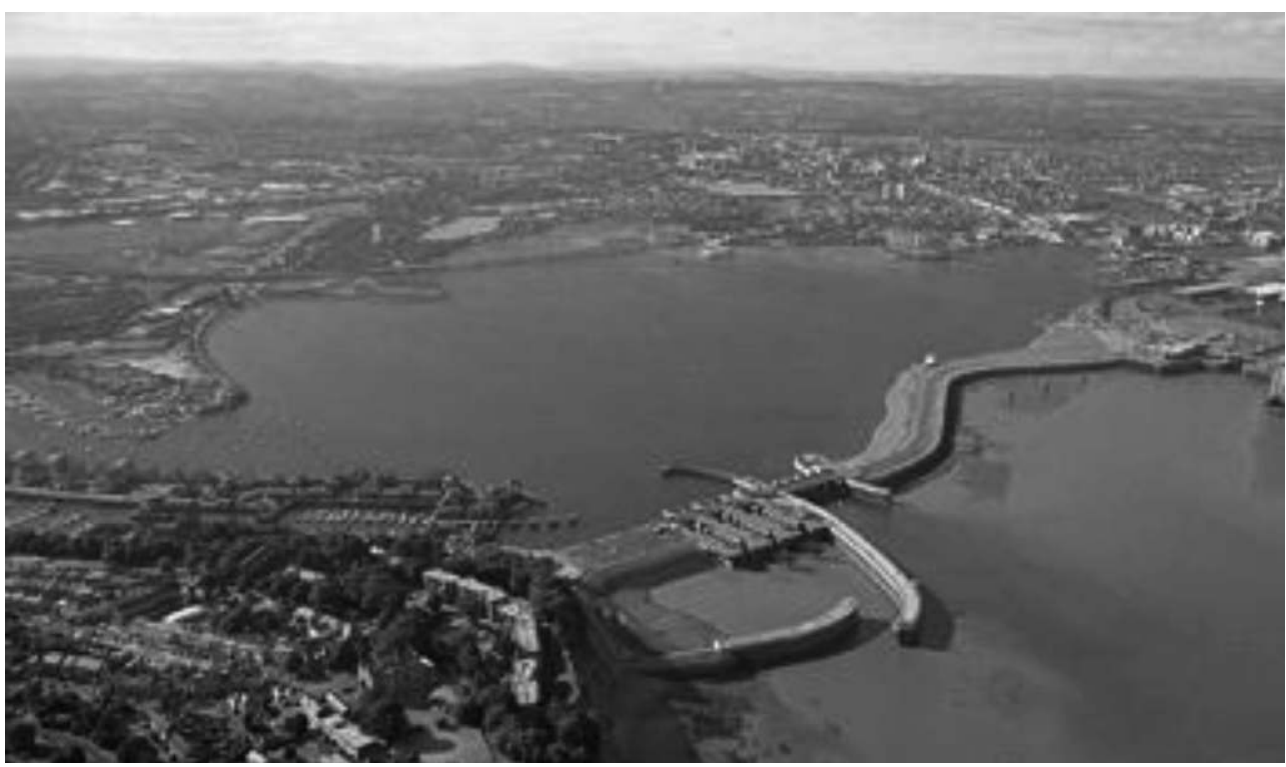

18 A baía constitui, de facto, o núcleo da imagem renovada da capital do País de Gales e do seu ímpeto inovador, enquanto local de encontro de grande apelo consumista e recreativo, onde se manifestam novas formas de visualizar a cidade e novas distribuições de poder (Short et al., 1993: 209).

\section{Inscrição e Perpetuação de Poder nos Espaços Urbanos de Cardiff}

19 Num mundo cada vez mais globalizado e globalizante, as cidades contemporâneas concorrem crescentemente entre si de modo a atraírem investimento público e privado, impulsionando-se como cidades atractivas a novos e actuais visitantes, residentes e trabalhadores. 


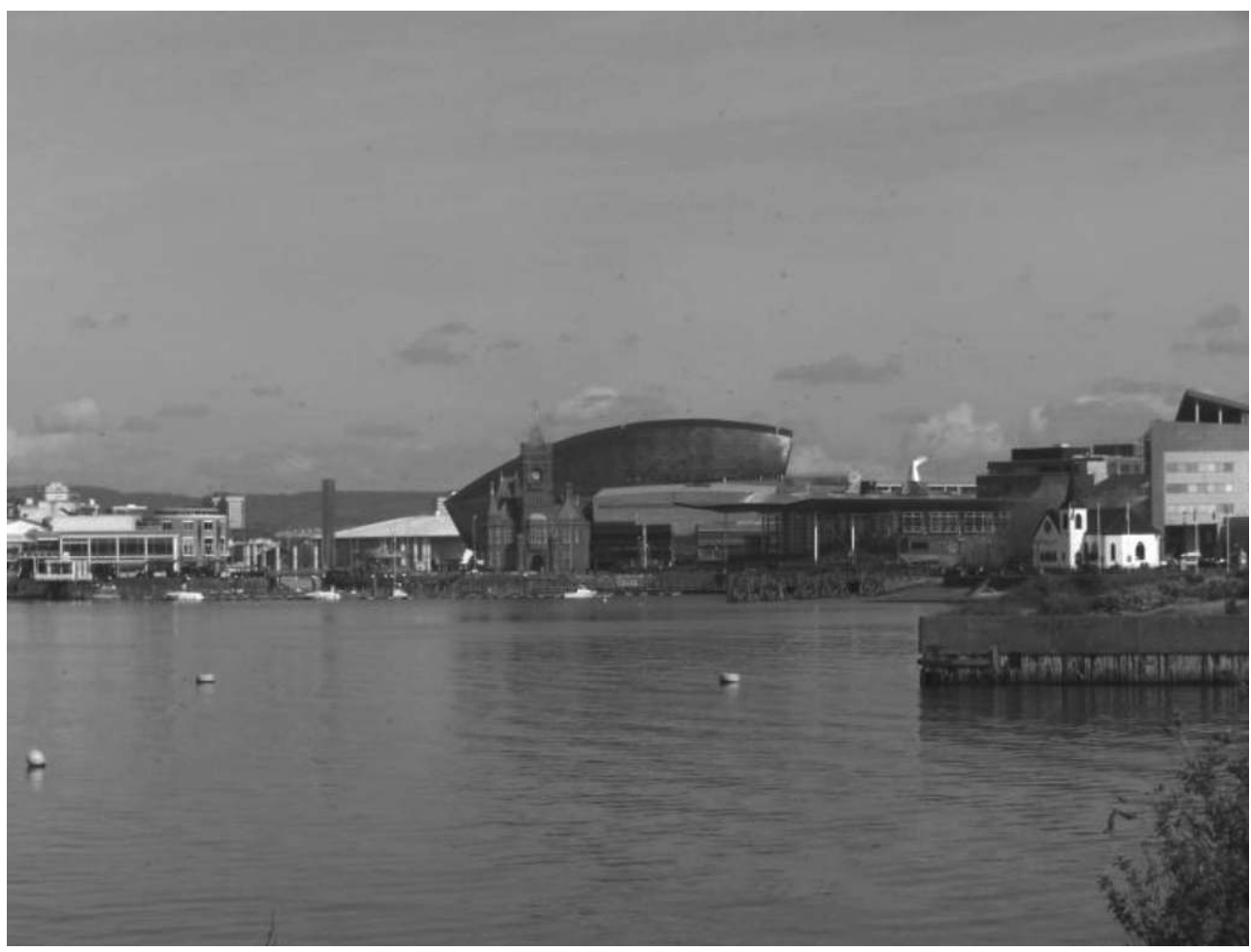

Com o principal desígnio de posicionar uma cidade no topo da lista das cidades mais visitadas a nível mundial, estas desenvolvem frequentemente uma nova imagética urbana, alicerçada num discurso promocional unificador. De acordo com Boyer (1996: 4-5), este discurso é construído por profissionais de arquitectura e planeamento urbano que entendem a competitividade urbana de forma despolitizada, direccionando a sua atenção para a promoção e atractividade da cidade, reforçando a sua imagética, vivência e capital cultural.

De forma a validar este discurso, a arte assume um entendimento funcional nos espaços urbanos. Tal sucede igualmente em Cardiff, onde a arte pública tem assumido contornos particulares. Em 1990, a Cardiff Bay Development Corporation publicou a Strategy of Public Art in Cardiff Bay. Este documento colocava a arte, e em particular a arte visual, no centro do processo de regeneração urbana e económica da Baía de Cardiff. Efectivamente, como salienta Miles (1997: 113), a arte apresenta-se como um meio eficaz para atrair visitantes a um determinado local, enaltecendo o ambiente visual envolvente. Nesta linha, a CBDC considerava que a arte pública na baía deveria melhorar e realçar todos os aspectos visuais da baía para benefício dos que nela viviam, trabalhavam e se divertiam (CBDC, 1990: 22). No entanto, Malcolm Miles, sem descurar o profissionalismo patente no documento, criticou fortemente esta estratégia, afirmando que a mesma "ignorava questões morais e sociais, a favor de futuros artísticos optimistas, negando assim uma leitura libertadora da arte através da capacidade de imaginação de futuros alternativos" (traduzido de Miles, 1997: 114). Para este autor, por outro lado, esta estratégia pretendia unicamente manter o lucro a curto prazo que caracterizava o governo Thatcher (Miles, 1997: 114).

De facto, Cardiff caracteriza-se hoje por um discurso dominante, relativamente consensual e convincente, orientado pelos esforços dos diferentes actores económicos em promover a cidade enquanto capital europeia atractiva, com vista a tornar-se uma 
"Cidade Líder do Reino Unido" até 2012, e uma "Capital Internacionalmente Competitiva" até 2020. Este discurso permanece enraizado na espectacularidade dos projectos de regeneração urbana e revitalização ribeirinha e em campanhas turísticas de contornos visuais e consumistas, com o intuito de atrair turistas, residentes e investidores à cidade, seguindo o exemplo de muitas outras cidades portuárias que ultrapassaram os efeitos da desindustrialização através do rejuvenescimento das suas frentes de água. Como Massey et al. (1999) salientaram, as cidades contemporâneas ocidentais têm adoptado diferentes estratégias de revitalização das suas imagem e influência, de modo a atrair novos turistas, residentes investidores. Tais estratégias visam uma renegociação do posicionamento destas cidades e das relações que estabelecem entre si, com vista a alterar positivamente a sua trajectória futura (Massey, Allen e Pile, 1999: 122).

Mas como pode a memória do passado de uma cidade ser preservada na reconstrução da sua imagem e dos seus espaços e como podem todos os intervenientes na construção de uma cidade ser representados nos espaços urbanos que a compõem?

Em Cardiff tem sido reproduzida e reconstruída uma memória parcial da história da cidade, a qual tem sido colocada ao serviço do consumo. O revitalizado Pier Head, o edifício mais icónico de Cardiff que acolheu no século XIX a administração do porto, e a Igreja Norueguesa, ambos adaptados como centros de exposição, assim como diferentes estátuas financiadas pelo Estado, esculturas e outras instalações e obras de arte incrustadas nas paredes e fachadas dos edifícios e monumentos, recordam as personalidades e momentos históricos relacionados com o legado marítimo e mineiro da cidade. No centro da cidade encontramos diferentes estátuas de individualidades de relevo na história da cidade e estátuas modernas de artistas locais, o castelo romano e o centro cívico, construído no início do século XX, e que incorpora obras de arte nas paredes e fachadas dos edifícios da Câmara Municipal, dos Tribunais, da Universidade de Cardiff e do Templo da Paz. Além destes, deparamo-nos ainda, nos jardins Alexandra, centrais a este complexo cívico, com vários memoriais comemorativos da participação galesa em várias guerras (como a Primeira e Segunda Guerras Mundiais, a Guerra das Malvinas ou a Guerra Civil Espanhola). A arte pública em Cardiff encontrase, assim, especialmente centrada na representação de períodos históricos previamente seleccionados, dos quais muitos indivíduos são deixados de fora.

Em 2005 o Cardiff Council publicou a Cardiff Public Art Strategy, cujos principais objectivos se prendiam com as políticas e práticas de exibição, com o incentivo às parcerias e com o envolvimento das comunidades na exibição da arte pública em Cardiff (Cardiff Council, 2005). Neste documento, a arte pública é entendida como uma mais-valia na construção da identidade cultural da cidade e na sua projecção aos níveis nacional e internacional, sendo os projectos comunitários incentivados, apesar de estes serem ainda escassos nos espaços públicos da cidade. Destaque-se, no entanto, o mural grafitado numa ponte sobre a linha ferroviária, em Adamsdown, ou o mural da escola de Kitchener, em Kitchener Road. 
Figura 6: Black Bridge, Adamsdown (in Cardiff Council, 2005: 6)

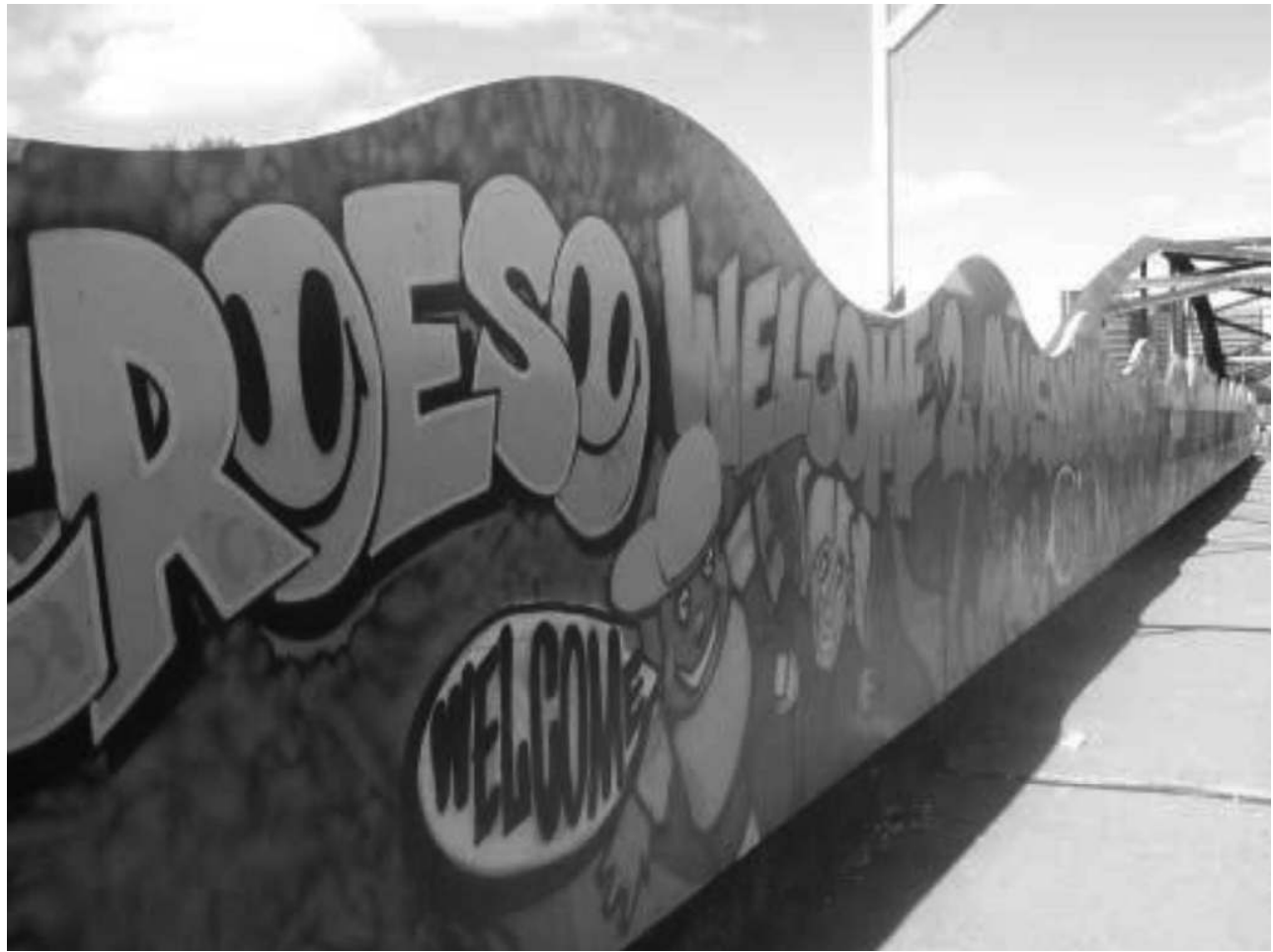

Figura 7: Mosaico na Escola de Kitchener, Kitchener Road (in Cardiff Council, 2005: 24)

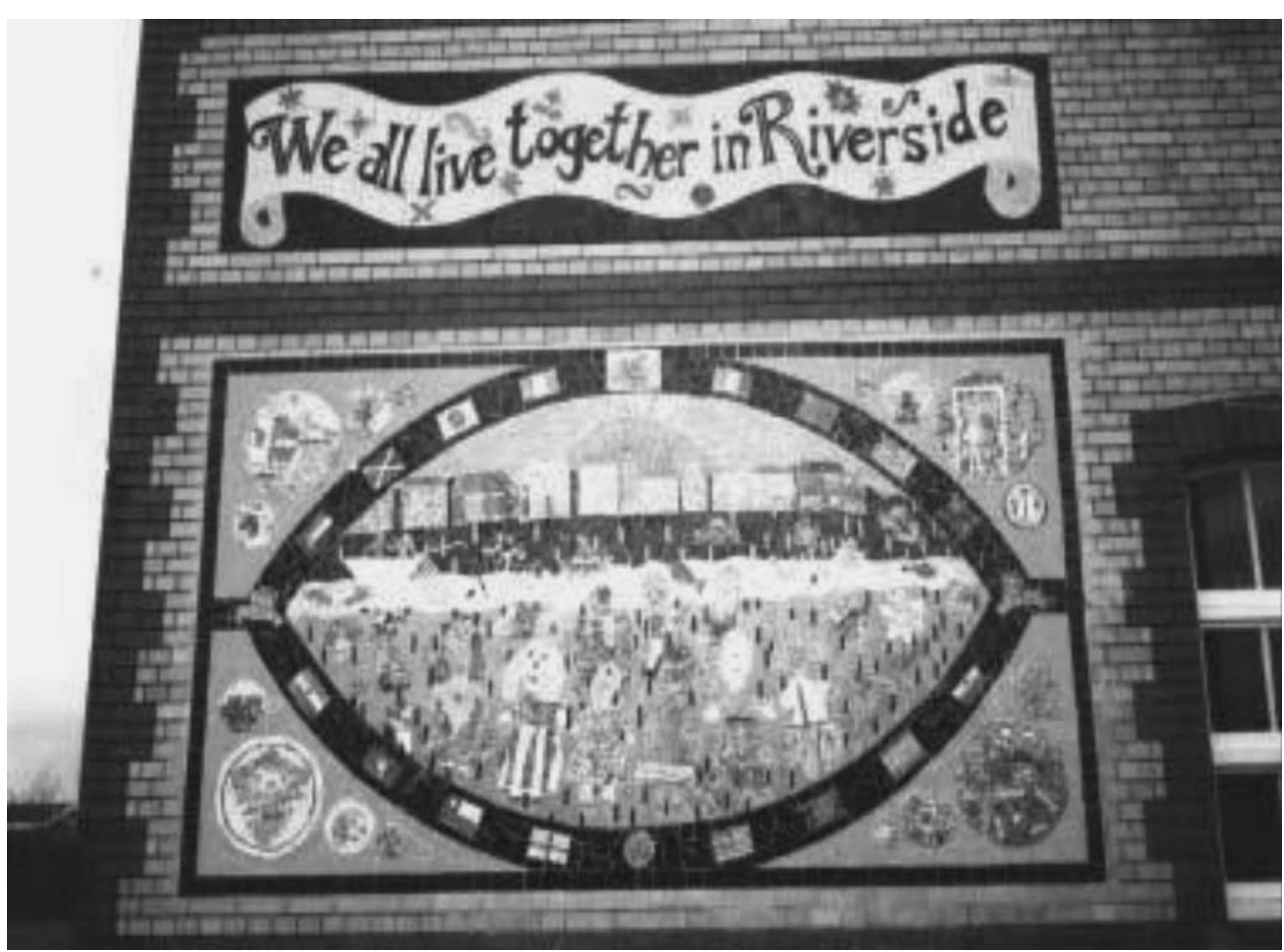

o passado de Cardiff enquanto porto de renome e especializado na exportação de carvão tem sido reconstruído para promover a cidade e servir os desígnios da actual sociedade de consumo, tornando-o visualmente acessível a todos. O passado e a história da cidade são, pois, parciais e reduzidos aos aspectos e momentos históricos não- 
problemáticos, que podem ser partilhados por todos na construção de uma identidade cultural urbana unificadora. Os episódios menos positivos ou controversos foram parcialmente silenciados e/ou votados ao esquecimento. Os espaços e as práticas urbanos em Cardiff são, de facto, articulados no enquadramento de um discurso dominante consensual, sujeito ao poder da ideologia pós-moderna do consumo visual, em que a arte pública "adorna" e "embeleza" as áreas de lazer, entretenimento e comércio e molda as novas imagem e identidade da cidade para o mundo como capital atractiva. Todavia, e de acordo com Boyer, os "desindustrializados", os "desterritorializados", os "deslocados" e os "desfavorecidos" não têm lugar neste "espectáculo construído” (Boyer, 1996: 2).

\section{Resistência ao Discurso Hegemónico da Cidade}

Como são então as identidades locais, estórias, memórias, necessidades e valores presentes e passados construídos e perpetuados nos espaços de Cardiff actualmente?

Numa época em que a cultura se encontra crescentemente enraizada na economia, os mais desfavorecidos são social, cultural e economicamente excluídos dos locais de consumo, lazer e entretenimento, uma vez que não lhes é possível aceder ao que estes locais lhes oferecem. Assim sendo, as questões avançadas por Sharon Zukin, "Whose Culture? Whose City?" em The Cultures of Cities (1995), e mais tarde reproduzidas e adaptadas por Malcolm Miles numa comunicação apresentada na conferência EU Futures, em 2007, tornam-se particularmente pertinentes, no sentido em que a condição de cidadania nas cidades contemporâneas se encontra dependente do poder económico que possibilita o acesso ao capital cultural e simbólico que a cidade oferece. No seguimento das considerações de Zukin e Miles, devemos, pois, questionar-nos que valores são retratados nos espaços urbanos, quem representam e qual o impacto que a representação da cidade tem na sua vida quotidiana e na produção cultural.

Os espaços e práticas que procuram resistir ao discurso dominante da regeneração e promoção turística de Cardiff enquanto capital internacionalmente competitiva e que dão voz aos mais desfavorecidos nesta pretendente a cidade mundial são conseguidos através da arte e de festivais comunitários. Os festivais, por exemplo, são particularmente importantes na expressão das comunidades e das vozes residuais da cidade, ainda que temporários, uma vez que se apresentam enquanto arte pública nos espaços urbanos apenas durante o seu tempo de realização, o que apenas permite imprimir discursos alternativos transitórios na paisagem urbana.

O papel mais decisivo na veiculação de vozes alternativas ao discurso hegemónico em Cardiff cabe ao Butetown History and Arts Centre (BHAC). Este centro foi criado em 1987, por Glenn Jordan, com o principal objectivo de questionar e desarticular as representações dominantes de Butetown (Jordan e Weedon, 1995: 138). Deve-se a este centro o facto de a comunidade de Butetown ser hoje uma "comunidade imaginada" (Anderson, 1983), moldada por uma memória colectiva, também ela imaginada, que se constrói nas diferentes representações visuais e escritas, quer dominantes, quer alternativas, que sobreviveram à comunidade histórica e que têm sido exibidas pelo centro ao longo dos seus mais de vinte anos de existência. O BHAC pretende assegurar que a história sócio-cultural das docas seja cuidadosamente preservada para a posteridade e fá-lo com o envolvimento activo dos residentes. Este centro contribui ainda para a consciencialização multicultural e multi-racial existente em Cardiff, 
recorrendo às artes como meio de produção de materiais, exposições e programas acessíveis a uma ampla audiência, e facilitando uma relação positiva entre as antigas e as actuais comunidades da baía de Cardiff (adaptado de Butetown History and Arts Centre).

31 As várias exposições que tem patenteado ao longo dos últimos anos e os projectos fotográficos activistas que o seu curador tem desenvolvido, como Somali Elders, retratos de anciãos Somali, ou Mothers and Daughters: Portraits from Multi-ethnic Wales, fotografias de mães e filhas de diferentes etnias residentes em Gales, constituem um importante contributo para a democratização cultural em Cardiff. Todavia, o escasso apoio financeiro e insuficiente reconhecimento que o centro tem recebido por parte das autoridades locais têm impossibilitado o BHAC de alcançar aquele que é o seu mais importante objectivo, o de criar o Bay People's Museum \& Arts Centre como contributo para a regeneração cultural da frente ribeirinha de Cardiff.

No final de 2010 será inaugurado no centro da cidade o museu The Cardiff Story. Este museu tem como principal missão apresentar-se como um local de exibição onde a história de Cardiff será narrada através do olhar dos seus residentes (Cardiff Council, 2008). No entanto, é pertinente questionarmo-nos se as vozes multiétnicas e discordantes do discurso dominante em Cardiff estarão também presentes neste museu e na história que este irá narrar sobre a cidade. Caso tal aconteça, demonstrará que as autoridades locais tomaram consciência dos erros dos seus anteriores líderes e reconheceram, por outro lado, a importância da diversidade étnica e cultural na história da cidade. Cardiff poderá, pois, ser promovida como verdadeiramente inclusiva e o museu da cidade constituirá um meio de comunicação da "singularidade e identidade locais" (Cardiff Council, 2008: 9).

Todavia, no discurso hegemónico da regeneração urbana espectacular que tem caracterizado Cardiff nas últimas décadas, muitas vozes e muitas estórias sobre o passado multiétnico e legado marítimo de Cardiff têm sido silenciadas. A memória do passado da cidade tem sido reconstruída apenas nos seus espaços intersticiais, sendo dedicada pouca atenção aos reais actores do seu passado: pessoas comuns cujas vidas estavam estreitamente associadas às docas ou à indústria mineira, que enfrentavam condições de habitação, educação e saúde miseráveis, que sofreram as privações de duas guerras mundiais e ajudaram em muitos outros conflitos armados fora do seu território. Estas eram pessoas de diversas nacionalidades, com diferentes credos religiosos e origens étnicas e culturais que, juntas, criaram a outrora reconhecida "metrópole mundial de carvão". No entanto, as únicas recordações expressas no espaço urbano que os residentes de Cardiff parecem ter hoje dos seus antepassados são a escultura de bronze de John Clinch, People Like Us, em Mermaid Quay, na Baía de Cardiff, representando um casal local com um cão e a escultura From Pit to Port, que apresenta a figura de um mineiro, em Britannia Quay, junto ao posto de turismo conhecido como The Tube, também na Baía. Ainda assim, ambas as esculturas foram financiadas pelas autoridades da cidade e concebidas por artistas estranhos ao espaço e ao tempo que estas obras de arte representam. 
Figura 8: People Like Us, Mermaid Quay (Ana Gonçalves, 2009)

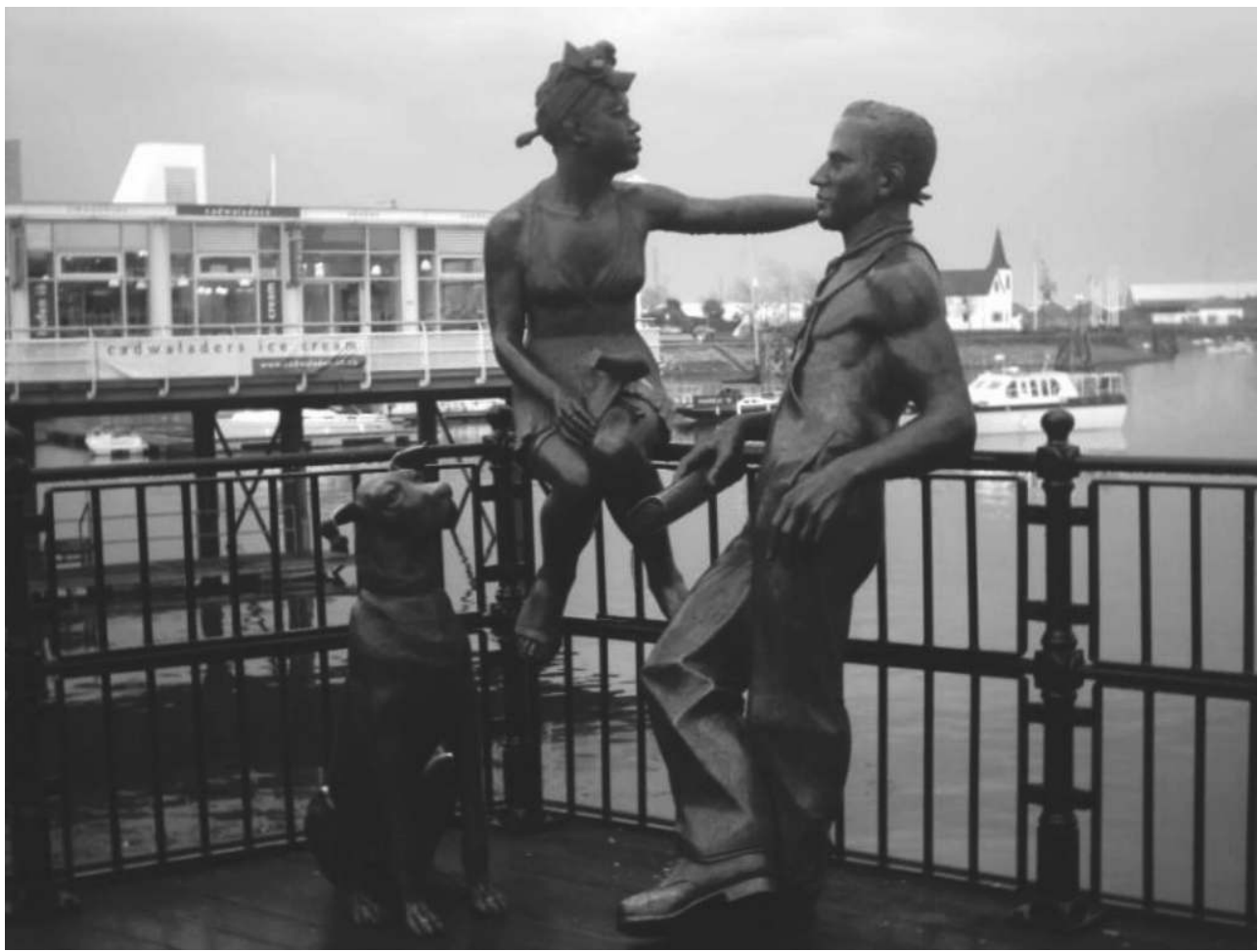

\section{Conclusão: Espaços Urbanos Inclusivos}

$34 \mathrm{Na}$ crescente visualidade e atractividade da sociedade actual, é importante que tenhamos o cuidado de não nos deixarmos enredar na "amnésia histórica" (Boyer, 1996: 65) do passado e de não negligenciarmos o contexto histórico e os actores que determinaram o desenvolvimento das cidades e que tornaram esse passado possível. 


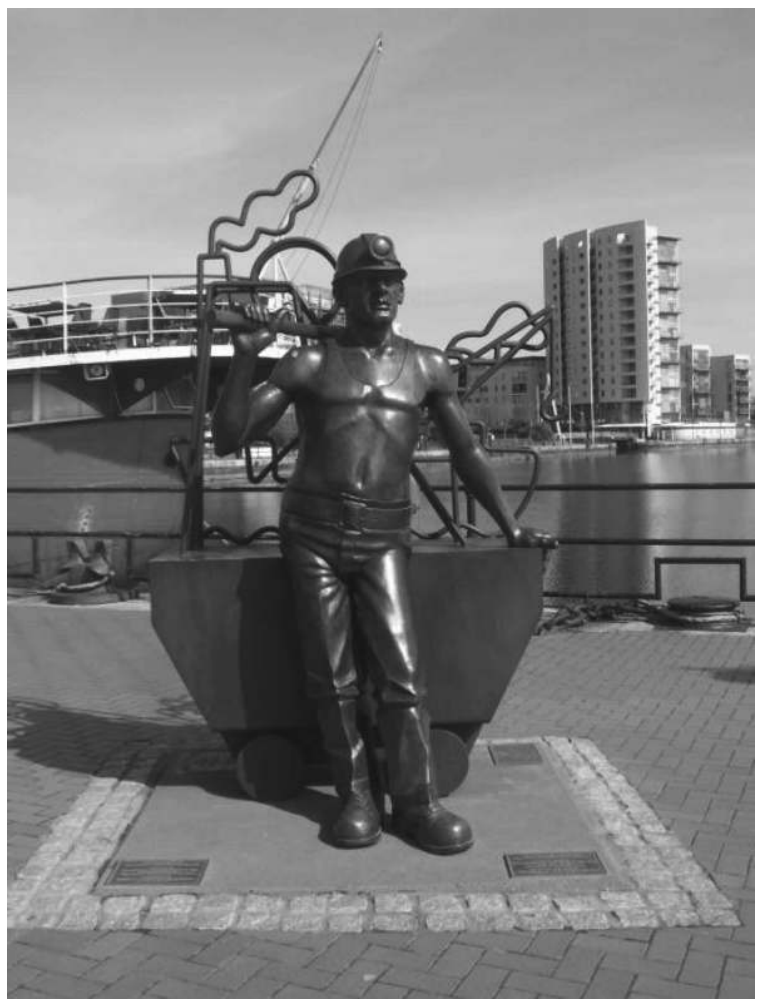

No caso de Cardiff é primordial relembrar a importância e prestígio de que a cidade desfrutou enquanto exportadora de carvão e as vidas daqueles que trabalhavam nas docas, na sua maioria membros da comunidade multiétnica de Butetown, que partilhavam práticas de identificação quotidianas, das quais podemos retirar muitas lições sobre relações sociais e valores humanos. A memória destes momentos e dos seus intervenientes, que contribuíram para a história e desenvolvimento da cidade, deve ser representada nos espaços públicos urbanos, para que a narrativa histórica, social e cultural da cidade seja completa e permita a gerações posteriores compreender a cidade onde vivem.

A baía de Cardiff tornou-se um projecto ribeirinho extraordinário, consagrado em larga medida ao lazer e à cultura, mas as ruas da frente ribeirinha de Cardiff já não são democratizadas como o eram no início do século XX. Promovem, antes, a polarização social e espaços de exclusão. Continuam a oferecer um "espectáculo contínuo" e uma "interminável série de quadros" (Hamilton in Hall, 1997: 110), mas os seus actores são agora os mais privilegiados, sendo a sua cidadania materializada na sua condição de consumidores. As ruas nas cidades contemporâneas são, pois, "menos humanizadas" e mais "ameaçadoras, mecanizadas, isolantes e monolíticas" (Hamilton in Bennett e Watson, 2002: 94), e as relações humanas mais efémeras e individualizadas.

As políticas de planeamento urbano devem, neste sentido, ter como objectivo principal serem verdadeiramente inclusivas e concebidas com vista ao bem-estar das pessoas e à sua apropriação dos espaços públicos, sem quaisquer barreiras de carácter social, cultural ou económico. As ruas e as praças nas cidades contemporâneas devem ser rehumanizadas e re-democratizadas e a arte desempenha um papel fundamental neste âmbito. As artes comunitárias devem ser incentivadas e financiadas pelo Estado, para que os diferentes espaços públicos possam realmente reflectir as práticas daqueles que 
vivem e se apropriam dos espaços urbanos. Deste modo, os residentes sentir-se-ão mais integrados nas cidades onde vivem e isso permitir-lhes-á criar um verdadeiro sentimento de empatia e de relação com o local. Com vista à resolução dos problemas da vivência nas cidades, é necessário acolher e maximizar a liberdade e autonomia que estas nos oferecem, tornando-as acessíveis a todos os grupos e classes sociais (Wilson, 1991: 9). Para tal, deve atribuir-se mais poder às comunidades locais nos espaços públicos e na arte que os integra para que a existência de passados alternativos, "a reconstrução do quotidiano e [a] redescoberta da alegria de viver na cidade" (traduzido de Miles, 1997: 18) sejam possíveis. Tal permitirá que as comunidades reclamem para si próprias o direito de construírem também os seus futuros. Conclui-se, pois, e de acordo com Miles, que um futuro urbano sustentável requer estratégias que celebrem de igual modo as áreas centrais e periféricas da cidade, que reclamem o carácter público do espaço urbano e que atribuam aos habitantes da cidade o poder de construírem eles próprios os conceitos da cidade que apropriam (Miles, 1997: 18).

\section{BIBLIOGRAFIA}

ANDERSON, B. (1983), Imagined Communities: Reflections on the Origins and Spread of Nationalism, London: Verso.

BENNETT, T. e D. Watson (eds.) (2002), Understanding Everyday Life, Oxford, UK and Cambridge, USA, Blackwell Publishers and The Open University.

BOURDIEU, P. (2001), Practical Reason: On the Theory of Action, Cambridge, Polity Press.

BOYER, M. C. (1996), The City of Collective Memory, London, MIT Press.

BUTETOWN HISTORY AND ARTS CENTRE [Disponível online: www.bhac.org].

CARDIFF COUNCIL (2008), Cardiff Museum Project - What story will you tell?, Cardiff, Cardiff Council.

CARDIFF COUNCIL (2005), Cardiff Public Art Strategy: Strategic Planning, Cardiff, Cardiff Council. CARDIFF BAY DEVELOPMENT CORPORATION (1990), Strategy for Public Art in Cardiff Bay, Cardiff, CBDC.

CARDIFF HARBOUR AUTHORITY [Disponível online: www.cardiffharbour.com]. CORDEIRO, G.I. e F. Vidal (orgs.) (2008), A Rua: Espaço, Tempo, Sociabilidade, Lisboa, Livros Horizonte.

DE CERTEAU, M. (1984), The Practice of Everyday Life, Steven Rendall (trans.), Berkeley, Los Angeles and London, University of California Press.

DUNCAN, J. S. (1990), The City as text: The politics of landscape interpretation in the Kandyan kingdom, Cambridge, Cambridge University Press.

FAINSTEIN, S. e S. Campbell (eds.) (1996), Readings in Urban Theory, Oxford, Blackwell Publishers. 
HALL, S. (1997), Representation: Cultural Representation and Signifying Practices, London, Sage Publications in Association with The Open University.

JORDAN, G. e C. Weedon (1995), Cultural Politics: Class, Gender, Race and the Postmodern World, Oxford, Blackwell Publishers.

KAVARATZIS, M. (2004), "From city marketing to city branding: Towards a theoretical framework for developing city brands" in Place Branding, Vol. 1 (1), pp. 58-73.

LEFEBVRE, H. (1991a), Critique of Everyday Life, Vol. I, J. Moore (trans.), London, Verso.

LEFEBVRE, H. (1991b), The Production of Space, Donald Nicholson-Smith (trans.), Oxford, Blackwell.

LLOYD, B. (1950), “Down the Bay” in Picture Post, 22 ${ }^{\text {nd }}$ April 1950.

MARIEN, M. W. (2002), Photography: A Cultural History, London, Laurence King Publishing.

MASSEY, D.; J. Allen e S. Pile (eds.) (1999), City Worlds, Understanding Cities, London and New York, Routledge in association with The Open University.

MILES, M. (2007), “Whose City? Whose Culture?” in Dr. Malcolm Miles Website [Disponível online: www.malcolmmiles.org.uk].

MILES, M. (1997), Art, Space and the City: Public Art and Urban Futures, London and New York, Routledge.

MULHERN, F. (1998), The Present Lasts a Long Time: Essays in Cultural Politics, Cork, Cork University Press in Association with Field Day.

O'NEILL, D. (2001), Tiger Bay and the Docks: The Story of a Remarkable Corner of the World, Derby, Breedon Books Publishing.

ROWLEY, G. (1994), “The Cardiff Bay Development Corporation: Urban Regeneration, Local Economy and Community”, Geoforum, 25 (3), Nottingham, Elsevier, pp. 265-284.

SHORT, J. R., et al. (1993), "Reconstructing the Image of an Industrial City", Annals of the Association of American Geographers, n.ㅇ 83 (2), pp. 207-224.

SINCLAIR, N. M. C. (2003), Endangered Tiger: A Community Under Threat, Cardiff, Butetown History and Arts Centre.

VISIT CARDIFF: THE OFFICIAL VISITORS' WEBSITE FOR CARDIFF [Disponível online: www.visitcardiff.com].

WAIKEEN, N. e J. Ryser (eds.) (2005), Making Spaces for the Creative Economy, Madrid, ISOCARP. WILSON, E. (1991), The Sphinx and the City, Berkeley, University of California Press.

ZUKIN, S. (1995), The Cultures of Cities, Massachusetts and Oxford, Blackwell Publishers, Ltd.

\section{RESUMOS}

Este artigo procurará questionar o modo como discursos dominantes e dissidentes têm sido construídos e perpetuados nos espaços públicos de Cardiff, capital do País de Gales. Outrora uma movimentada cidade portuária e anfitriã de uma comunidade trabalhadora multiétnica singular, Cardiff tem sofrido profundas transformações urbanas, apresentando hoje uma frente ribeirinha completamente rejuvenescida. Edifícios históricos articulam-se na paisagem urbana com modernos edifícios-âncora num discurso dominante aparentemente consensual entre o passado e 
o presente, sujeito à ideologia pós-moderna do consumo visual espectacular, onde o lazer e o entretenimento influenciam as novas imagem e identidade da cidade para o mundo. Esta paisagem silencia, todavia, muitas vozes e apaga muitas estórias do passado marítimo e multiétnico de Cardiff, influenciando o modo como as identidades individuais e colectivas se constituem. Excepção parece ser o Butetown History and Arts Centre, onde a democracia cultural procura dar voz aos discursos minoritários da cidade, e o qual merecerá, pois, particular atenção neste artigo.

This paper will question the way in which dominant and counter-hegemonic discourses have been constructed in the public spaces of Cardiff, the capital of Wales. Once a busy port city and home to a unique working-class multiethnic community, Cardiff has undergone deep urban changes, presenting today a completely renewed waterfront. Historical buildings mingle with modern flagship buildings in the urban landscape, in a dominant and rather consensual discourse between the past and the present, subjected to the post-modern ideology of spectacular visual consumption, where leisure and entertainment influence the new image and identity of the city to the world. This landscape silences, however, many voices and erases many stories from the maritime and multiethnic past of Cardiff, influencing the formation of individual and collective identities. The exception seems to be the Butetown History and Arts Centre, where cultural democracy aims at giving voice to the city's minority discourses, and which will, therefore, deserve closer attention in this paper.

\section{ÍNDICE}

Keywords: Cardiff, urban interstices, everyday practices, power

Palavras-chave: Cardiff, interstícios urbanos, práticas quotidianas, poder

\section{AUTOR}

\section{ANA GONÇALVES}

Escola Superior de Hotelaria e Turismo do Estoril (CESHTE) ana.goncalves@eshte.pt 